\title{
KANT E A CONSIDERAÇÃO TRÁGICA DA EXISTÊNCIA EM NIETZSCHE
}

\section{KANT UND CONSIDERATION THE TRAGIC EXISTENCE IN NIETZSCHE}

Marco Sabatini*

\section{RESUMO}

Este trabalho analisa uma influência positiva de Kant nos textos juvenis de Nietzsche, demonstrando que a filosofia kantiana foi um passo em direção à consideração trágica da existência após Sócrates. Sob este veio, problematiza-se o otimismo socrático enquanto destruidor da mais elevada forma grega de afirmação da vida, isto é, a Tragédia. Esse otimismo, potencializado no conhecimento científico, teria inibido o impulso dionisíaco por meio da confiança ilimitada na sabedoria: o que, para Nietzsche, teria sido apenas a ilusão de um estado moralizador e escravo. No entanto, em $O$ nascimento da Tragédia, o jovem filósofo cria que o impulso dionisíaco estava em um processo de ruptura das barreiras da cientificidade moderna. Dessa forma, o esforço de Kant em delimitar a razão seria a primeira etapa contra o otimismo socrático em direção ao conhecimento trágico da vida.

PALAVRAS-CHAVE: Metafísica. Conhecimento. Tragédia. Arte. Vida.

\begin{abstract}
This work analyzes a positive influence of Kant on juvenile texts of Nietzsche, demonstrating that the Kantian philosophy was a step toward the tragic world consideration after Socrates. Under this vein, it problematizes the Socratic optimism while the highest destroyer Greek form of affirmation of life, ie the tragedy. This optimism, boosted in scientific knowledge, would have inhibited the Dionysian impulse by unlimited trust in the wisdom: what for Nietzsche would have been only the illusion of a moralizing and slave state. However, in The Birth of Tragedy, the young philosopher believed that the Dionysian impulse was in the process of breakage the barriers of modern scientificity. Thus, the effort of Kant in delimit the reason would be the first step against the Socratic optimism toward the tragic knowledge of life.
\end{abstract}

KEYWORDS: Metaphysics. Knowledge. Tragedy. Art. Life.

\footnotetext{
* Mestre e doutorando em Filosofia pela Universidade Federal de São Paulo (Unifesp). E-mail: marco_rsabatini@hotmail.com.
} 


\section{O otimismo socrático e a tragédia}

Alguns anos antes de se tornar docente na Universidade da Basiléia, Nietzsche confessava em um escrito autobiográfico que a matéria da maior parte dos cursos não lhe interessava "em absolutamente nada, senão só a forma na qual o acadêmico transmitia sua sabedoria aos ouvintes" (NIETZSCHE, 1997, p. 4). O que interessava ao filósofo era o despertar do pensamento crítico que o mestre causava em seu aluno, adornando outra questão ainda mais fundamental: a vida. Neste percurso, $O$ nascimento da tragédia reverberou intensamente algo que Nietzsche já objetivara de alguma forma: a aproximação e a afirmação da vida.

Com a influência de $O$ mundo como vontade e representação, Nietzsche identificou com a Vontade schopenhaueriana uma parte humana íntima e inacessível, que, porém, se afastava da própria noção de Schopenhauer. Para o filósofo pessimista, o mundo é apenas a sua representação, "é sempre a VONTADE, única a constituir o outro lado do mundo" (SCHOPENHAUER, 2005, p. 45). No entanto, para o jovem Nietzsche, esta "vontade" não opera no registro metafísico; mas em um campo de forças instintivas do próprio corpo concepção que, em sua filosofia de maturidade, fortalecer-se-á com os estudos fisiológicos.

\footnotetext{
Até mesmo o conjunto da vida pulsional, o jogo dos sentimentos, sensações, afetos, atos volitivos, é conhecido por nós - como tenho que intercalar aqui contra Schopenhauer -, de acordo com o mais preciso auto-exame, apenas como representação, não segundo sua essência: e nós bem podemos dizer que até mesmo a "vontade" de Schopenhauer nada mais é que a forma mais universal da aparência de algo para nós, de resto completamente indecifrável. (NIETZSCHE, 2007b, p. 170171)
}

Algo basilar se manifesta no próprio corpo, mas cujo acesso paira sobre as sensações de prazer e desprazer que exteriorizam apenas um mundo simbólico sobre si mesmo (NIETZSCHE, 2007b, p. 170-171). Esses símbolos enquanto representações do próprio corpo revelam a exaltação ou a inibição dos prazeres e dos desprazeres; consequentemente, se transformam em uma medida analítica de afirmação ou negação da própria vida. Neste sentido, Nietzsche diz: "minha filosofia, um platonismo invertido: quanto mais afastado do ser verdadeiro, tão mais puro e belo ele é. A vida na aparência como meta” (1988c, p. 199). Pois, "o ser verdadeiro" seria apenas uma representação que não atinge o fundamento do próprio homem senão enquanto símbolos de determinadas forças pessoais. 
Disso decorre a crítica de Nietzsche ao socratismo - que "é mais antigo que Sócrates" (NIETZSCHE, 2007e, p. 238). O socratismo confrontaria a parte instintivamente criadora do homem. Através do ensinamento de que a beleza deriva-se de um estado consciente, demais configurações humanas seriam absurdas. Esta constatação rebaixa o trágico diante do filósofo socrático que fundamenta seu saber na lógica e na dialética. Com a linearidade causal, opõemse imagens desconexas que Sócrates classifica como transformações e possessões semelhantes às epifanias dionisíacas das Bacantes (PLATÃO, 1988, p. 51). No entanto, para Nietzsche, estas configurações dionisíacas não seriam apenas momentâneas loucuras; mas, sim, encarnações de estados mais primitivos onde os espectadores tornavam-se "servidores intemporais de seu deus, vivendo fora do tempo e fora de todas as esferas sociais" (NIETZSCHE, 2007g, p. 57).

O problema da tragédia perante Sócrates surge, pois, "para poder respeitar os próprios limites, há que conhecê-los" (NIETZSCHE, 2007c, p. 257). Se um determinado estado impossibilita o "conhecimento" de si mesmo enquanto "uma renúncia do indivíduo através do ingresso em uma natureza estranha" (NIETZSCHE, 2007g, p. 57), então um dos principais pilares da filosofia socrática está ameaçado. Se não se sabe sequer o nome, então como poderia conhecer-se a si mesmo? O fato é que este desconhecimento resulta da irrupção dos limites que a civilização construíra para se proteger da própria fera humana e dos sofrimentos do mundo. Assim, se evidencia "a mentira da civilização a portar-se como a única realidade" (NIETZSCHE, 2007g, p. 54) diante de imagens mais reais enquanto eco de sensações de prazer e desprazer de cada trágico. "Se, até então, sentia-se protegido, na posse do que há de mais real, isto é, desse mundo seguro da realidade, tudo se desfaz como um véu de névoa, a ilusão da individuação o abandona, o homem é engolido pelas trevas púrpuras das profundezas" (ROHDE, 2005, p. 36-37). Dessa forma, o comedimento de Sócrates perante a tragédia não era apenas uma questão heurística; mas, sobretudo, existencial - em relação ao sofrimento e ao desespero do homem.

A solução para tal ameaça teria sido imputar no âmago da tragédia a mesma estrutura lógica do socratismo, eliminando o pessimismo trágico. "Esse elemento otimista que, uma vez infiltrado na tragédia, há de recobrir pouco a pouco todas as suas regiões dionisíacas e impelilas necessariamente à destruição" (NIETZSCHE, 2007g, p. 87). Isso porque a dialética socrática objetivaria triunfar perante todos os empecilhos que lhe surgissem à frente. A racionalidade que se expressa em sua maior força com Sócrates evitava os atos desmesurados que levavam à violência e ao sofrimento. É assim que Nietzsche interpreta a tragédia de 
Eurípides: o auge do socratismo que se fortalecia desde o deslocamento do coro trágico por Sófocles. Em $O$ nascimento da tragédia, Eurípides aparece, por conseguinte, apenas como "o arauto de uma nova forma de criação artística" (NIETZSCHE, 2007g, p. 81). E a crença de que Sócrates “colaborava com Eurípides na composição das peças deste último" (LAÊRTIOS, 2008 , p. 52) reforçava a tese de Nietzsche que relacionava a dialética euripidiana ao socratismo.

Com a racionalidade socrática, velava-se então o fundamento que levava o homem ao desespero: velava-se o próprio elemento dionisíaco. Através de representações ilusórias, novamente se tinha aquela sensação anterior ao efeito da tragédia: ou seja, uma sensação de segurança diante dos tormentos do mundo. Assim, o conhecimento socrático resistia ao trágico com a "inabalável fé de que o pensar, pelo fio condutor da causalidade, atinge até os abismos mais profundos do ser e que o pensar está em condições, não só de conhecê-lo, mas inclusive de corrigi-lo" (NIETZSCHE, 2007g, p. 91). Entre as forças do homem, transpassaria uma ética corretiva através dos ensinamentos como nada em excesso e conhecete a ti mesmo. Se não podemos atingir o Bem platônico, podemos, ao menos, levar uma vida conforme a sua (PLATÃO, 2006 e 1973a); da mesma forma, a ética socrática atuaria sobre o corpo, resignando-o perante a sua ignorância: "algema-o o prazer socrático do conhecer e a ilusão de poder curar por seu intermédio a ferida eterna da existência" (NIETZSCHE, 2007g, p. 106).

No entanto, para Nietzsche, esta tentativa de vida seria apenas uma forma degenerada da mesma: excluindo-se o caráter desmesurado, instintivo e inconsciente, nega-se a própria existência - que, além das instituições sociais, não possui nenhuma definição de como se deve viver. Por conseguinte, o ensinamento socrático seria apenas uma força moralizadora reforçada pela pretensão de um conhecimento ilimitado - e que se afasta consideravelmente da vida. Será contra este "otimismo que se presume sem limites" (NIETZSCHE, 2007g, p. 107) que, para Nietzsche, Kant dará um passo em direção à consideração trágica.

\section{Kant e o conhecimento}

Em um fragmento póstumo de 1872, Nietzsche afirma que a "posição da filosofia mudou desde Kant" (1988c, p. 517). Não surpreende, porém, essa assertiva que tantos outros críticos e filósofos já haviam anunciado. Menos ainda, quando evidenciado o engenho da Crítica da Razão Pura ao analisar "suas fontes e limites" a fim de mantê-la "isenta de erros" 
(KANT, 1994, p. 53). Essa análise resulta na limitação dos conhecimentos da metafísica, ou seja, na impossibilidade de "ultrapassar os limites da experiência possível” (KANT, 1994, p. 21). Caso contrário, tem-se apenas a insegurança de discursos retóricos desprotegidos da armadura científica, pois ela "se eleva inteiramente acima das lições da experiência, mediante simples conceitos (não, como a matemática, aplicando os conceitos à intuição)" (KANT, 1994, p. 18-19). Se, “pelo menos para nós homens" (KANT, 1994, p. 61), o conhecimento se relaciona com o objeto - independente, inicialmente, desta forma de relação - através das afecções que recebemos dos fenômenos, então a sensibilidade é a intermediária entre os objetos dados e o entendimento que os pensa (KANT, 1994, p. 61). Somos então afetados intuitivamente pelos fenômenos que precedem o entendimento; ele "é, em contrapartida, a capacidade de produzir representações" (KANT, 1994, p. 89).

Assim, estabelece-se uma ligação necessária entre a intuição e o entendimento em que, a primeira, permite o conteúdo e, o segundo, o determina através do conceito, de modo que "pensamentos sem conteúdos são vazios; intuições sem conceitos são cegas” (KANT, 1994, p. 89). Não se pode então descartar tão facilmente a sensibilidade. Por conseguinte, “devemos, pelo menos, pensar os objetos como coisas em si embora os não possamos conhecer" (KANT, 1994, p. 25); a coisa em si poderia ser apenas pensada, mas não conhecida, pois o conhecimento necessita da demonstração de sua possibilidade - seja empírica ou racional. O estudo do Ser que a filosofia platônica legou é possível, por conseguinte, como pensamento e não como conhecimento.

Aqui, há um nítido confronto entre a filosofia kantiana e o conhecimento platônico que possui, segundo Nietzsche (2007g, p. 75-84), ligação direta com o socratismo. Para Platão, o conhecimento se relaciona com a verdade, senão, é apenas uma opinião. Almejando o ser, investiga possíveis características que o formam, que constituem a sua essência. Tal essência define algo de modo inconfundível, porque, se contrário, ele deixaria de ser o que é. Consequentemente, o engano, o incerto, o erro, o mutável se contrapõem a esse conhecimento. Assim, existiriam duas esferas para a filosofia platônica: a realidade e a ilusão. O plano da realidade não é o que vivemos, mas uma "dimensão" outra cuja verdade é inalcançável a partir da constituição vivente do ser humano devido os constantes vícios de nossos corpos que impossibilitam o pleno conhecimento. A verdade estaria além do próprio homem e o conhecimento independeria dele, a quem restaria apenas descobrir essências.

Kant "aproxima" o homem do fenômeno; elimina a essência e a verdade enquanto conhecimento metafísico. Que é a verdade - para Kant? "A definição nominal do que seja a 
verdade, que consiste na concordância do conhecimento com o seu objeto, admitimo-la e pressupomo-la aqui" (KANT, 1994, p. 94). Com a impossibilidade da coisa em si enquanto conhecimento, não existe mais nenhum Ser metafísico que regula "padrões" intersubjetivos do conhecer. Ao contrário, os objetos estariam regulados pelo próprio conhecimento - o que dá à ciência a prerrogativa da criação e descoberta logicamente racionais. Nota-se, no entanto, que não é a coisa em si que se torna regulada; mas, sim os objetos do conhecimento. Para não recair em absurdos, no ceticismo e no psicologismo e racionalismo extremos, o conhecimento estaria adequado pelas regras do entendimento.

Uma lógica interna ao entendimento seria os critérios de verdade para Kant. Esses critérios referem-se, no entanto, somente ao modo da verdade, isto é, do "pensamento em geral e, como tais, são certos mas não suficientes. Porque, embora um conhecimento seja perfeitamente adequado à forma lógica, isto é, não se contradiga a si próprio, pode todavia estar em contradição com o objeto" (KANT, 1994, p. 94). Por conseguinte, a lógica se apresenta como um critério de verdade - que é a validade "para todos os conhecimentos, sem distinção de seus objetos" (KANT, 1994, p. 93) -, mas não a verdade propriamente. Ela não acrescenta nada ao conhecimento, como Kant dissera no Prefácio da Segunda Edição: “os limites da lógica estão rigorosamente determinados por se tratar de uma ciência que apenas expõe minuciosamente e demonstra rigorosamente as regras formais de todo o pensamento" (KANT, 1994, p. 15-16); o seu sucesso reside em verificar as contradições internas do entendimento com o conteúdo. Assim, a verdade emerge através das regras formais que a lógica impõe ao entendimento enquanto que a falsidade resulta da discordância entre o conhecimento e o seu objeto. Garante-se, ao menos, a proteção diante de "uma arte sofística de dar verniz de verdade à ignorância" (KANT, 1994, p. 95). O conhecimento é então uma representação que não atinge diretamente quaisquer essências metafísicas. Ele "provém de duas fontes fundamentais do espírito, das quais a primeira consiste em receber as representações (a receptividade das impressões) e a segunda é a capacidade de conhecer um objecto mediante estas representações (espontaneidade do conceito)" (KANT, 1994, p. 88).

“Assim Kant inverte o problema" (LEBRUN, 2001, p. 21). Se, para Platão, o erro era o reflexo de um paradoxo, pois a sua impossibilidade era resultado da ignorância (como a ignorância refere-se ao não ser e, do não ser, nada se pode dizer), então ou o silêncio predominaria em uma neutralidade que não pode julgar o errado ou o saber teria uma condição ilimitada de conhecimento - já que sempre se pode falar do que existe - e consequentemente falar do que não existe - o que seria absurdo. “Ou não há opinião falsa, ou 
podemos não saber o que sabemos" (PLATÃO, 2010, p. 292). Mas, quando Kant cinde o contato direto com a coisa em si, já não se fala mais nos termos platônicos. O conhecimento não possui ligação com a essência do Ser, da mesma forma que a ignorância não representa o não-ser. "A falsidade não é mais uma falta com a relação a uma verdade sempre segura (desde que eu preste atenção), mas um descuido quanto à fragilidade do saber" (LEBRUN, 2001, p. 21). A falsidade torna-se uma incoerência interna do pensamento. Estas questões resultam em algo mais drástico: se a falsidade e o erro, o conhecimento e a ignorância não são mais regulados metafisicamente, então, cabe ao homem, a construção e não apenas a descoberta de seu saber.

\section{Kant e a consideração trágica da existência em Nietzsche}

O interesse de Nietzsche em Kant, aqui, não é epistemológico, mas existencial. A limitação do conhecimento metafísico por Kant permite a Nietsche restringir o socratismo do campo trágico. Eliminado o racionalismo presente nas artes modernas, Nietzsche acredita poder identificar elementos de uma época mais primitiva no homem. A importância destas configurações menos civilizadas revelaria estados em que ele é criador de si mesmo; ou seja, em que as leis da civilização não impediriam o florescimento de seus instintos. Não é um retorno à barbárie, mas, sim, um lugar em meio à civilização em que um lado mais obscuro se expressa sem que, com isso, ameace a própria vida.

O dionisíaco puro é aniquilador, o apolíneo puro é patológico. Isto é, a desmesura, o obscurantismo humano, o seu horror, o seu instinto, se somente existissem sem nenhuma lei e em todo o momento, levaria sem dúvida o homem à destruição de si e dos outros. No entanto, somente a medida, o controle, as leis, a sociedade, da mesma forma, aprisioná-lo-ia em uma situação bárbara de escravo cuja vida seria impossível em sua plenitude. A tragédia seria a mistura do apolíneo e do dionisíaco e, por isso, uma fissura em meio à cultura dórica enquanto reverberação de tempos anteriores; "e o efeito mais imediato da tragédia dionisíaca é que o Estado e a sociedade, sobretudo o abismo entre um homem e outro, dão lugar a um superpotente sentimento de unidade que reconduz ao coração da natureza" (NIETZSCHE, 2007g, p. 52).

Segundo Nietzsche, quando o otimismo socrático invade a tragédia visando uma existência mais segura e menos dolorida, paradoxalmente, ele elimina a própria segurança da vida através da crença de que a sua racionalidade pode evitar todos os males, e "vai pouco a 
pouco ao encontro de uma horripilante destruição" (NIETZSCHE, 2007g, p. 107). O conhecimento trágico permite, ao contrário, através do prazer e da dor, que as verdades consideradas mais sólidas pela crença cotidiana se desfaçam por entre os dedos. Um mundo inexplicável é um palco em que quaisquer constituições são possíveis. Não é uma adoção da filosofia kantiana. A música, uma das noções centrais em $O$ nascimento da tragédia por exemplo, não possui a mesma importância em Kant e Nietzsche. Neste sentido peculiar, ele interpretará a Crítica da Razão Pura como uma poderosa foice que corta as raízes regadas por Sócrates e Platão.

Para Nietzsche, o sentimento trágico revelou a "miséria universal" (NIETZSCHE, 2007g, p. 109) do otimismo socrático. Grandes homens afetados de tal maneira perceberam o fundo ilógico da metafísica a se considerar como ciência e a inquiriram "a fím de expor os limites e condicionamentos do conhecer em geral e, com isso, negar definitivamente a pretensão da ciência à validade universal e a metas universais" (NIETZSCHE, 2007g, p. 108). Se, segundo Kant, o conhecimento parte da sensibilidade, então a questão se resume em: diferentes sensações levam a diferentes conhecimentos? Vedado o acesso à essência do universo, o saber se apresenta "apenas em suas exteriorizações figurativas" (NIETZSCHE, 2007b, p. 170), isto é, enquanto representações.

As representações derivariam de estímulos nervosos, transmutados em imagens e sons. "Um estímulo nervoso, primeiramente transposto em uma imagem! Primeira metáfora. A imagem, por sua vez, modelada em som! Segunda metáfora” (NIETZSCHE, 1974b, p. 55). Dessa forma, as representações resultariam do corpo; e o corpo consequentemente as criaria segundo diversas sensações. Determinados contextos forjariam representações de acordo com determinadas sensações, e determinadas representações seriam sentidas diferentemente conforme cada sensação, de modo que diferentes formas de existência considerariam diversamente o mundo. Não à toa, em Schopenhauer como educador, Nietzsche diz que "somente em pouquíssimos homens Kant atuou vivamente e transformou sangue e seivas" (1974a, p. 79), pois a sua filosofia corajosamente rebaixa o grau de certeza que se tinha das condições essências do homem - como a sua própria "Liberdade".

A filosofia kantiana seria assim a demonstração fisiológica de um corpo que não acreditava na segurança do otimismo socrático - e, como a filosofia de Schopenhauer, representaria uma forma diferente de consideração do mundo. "A enorme bravura e sabedoria de KANT e de SCHOPENHAUER conquistaram a vitória mais difícil, a vitória sobre o otimismo oculto na essência da lógica, que é, por sua vez, o substrato de nossa cultura" 
(NIETZSCHE, 2007g, p. 108). Por isso, para Nietzsche, Schopenhauer enfrentou o "desespero da verdade" sob a influência de Kant. "Este perigo acompanha todo pensador que toma seu caminho a partir da filosofia kantiana, pressuposto que seja um homem vigoroso e inteiro no sofrer e desejar, e não apenas uma sacolejante máquina de pensar e de calcular" (NIETZSCHE, 1974a, p. 79). A Crítica da Razão Pura atuaria diversamente e originalmente conforme cada pessoa. O que interessa a Nietzsche é exatamente este desespero diante da Verdade metafísica, pois também significa o desmoronamento da certeza, reduzindo o homem civilizado a uma "mentirosa caricatura" (NIETZSCHE, 2007g, p. 54).

O que é a verdade - para o jovem Nietzsche? "Um batalhão móvel de metáforas, metonímias, antropomorfismos, enfim, uma soma de relações humanas [...]: as verdades são ilusões, das quais se esqueceu que o são" (NIETZSCHE, 1974b, p. 56). Apenas uma ilusão que se deriva de estímulos nervosos, uma representação metafórica que traduz as próprias sensações do corpo cujo significado está somente no representador enquanto ele significa. "Pouco a pouco, a filosofia perde a rédea da ciência [Wissenschaft] de suas mãos" (NIETZSCHE, 1988c, p. 425). Dessa forma, para se buscar a verdade - encontrar a essência da coisa, como queria Sócrates e Platão -, devem-se anular totalmente as criações de alguém; caso contrário, não há conhecimento, mas opinião, como foi visto acima. Ora, se a verdade é a revelação da realidade, ou melhor, a descoberta de uma propriedade, de uma lei essencial a um objeto, então nada se tem para criar ali, nada é do próprio homem.

Não sendo, portanto, uma criação humana para Sócrates e Platão, o conhecimento é uma descoberta de essências. Dessa forma, se, segundo Nietzsche, não há nada no homem que não seja uma vontade e não existe nada além de seus próprios sentidos, então qual é o perigo almejar "verdades" como as de Sócrates e Platão? Inutilizar o próprio homem - o seu desejo, a sua vontade, o seu instinto, a sua criação, o seu pensamento. A verdade seria, segundo o método socrático-platônico, uma transfiguração da moral, em algo disciplinador e condutor. Por isso que, ao eliminar a ligação metafísica com o conhecimento, Kant elimina o princípio socrático que moralizava o homem. "Em sua 'coisa em si', ninguém poderá contar, como se fosse um princípio domador" (NIETZSCHE, 1988c, p. 425).

Dessa forma, Kant faria parte de um grupo de homens - como Wagner e Schopenhauer - cuja sensação irrompeu o otimismo socrático ao sentir os sofrimentos do mundo, ao perceber que aquele significado não provinha de dimensões metafísicas, mas, sim, do próprio homem -, portanto, que toda a significação era apenas uma criação humana. Semelhantemente, seria esta forma de sentir o mundo que a tragédia causava em seus 
espectadores: "para onde aponta o mistério dessa unidade entre a música alemã e a filosofia alemã, se não para uma nova forma de existência, sobre cujo conteúdo só podemos informarnos pressentindo-o a partir de analogias helênicas?” (NIETZSCHE, 2007g, p. 117) Aponta para onde a própria ciência não pode alcançar; para onde a explicação é realizada somente através da arte. Para a consideração trágica! - consideração, esta, que não estaria domesticada por nenhuma moral.

O trágico seria "parecido ao que existe entre o eterno cerne das coisas, a coisa em si, e o conjunto do mundo fenomenal" (NIETZSCHE, 2007g, p. 54). O homem posto como fenômeno de si mesmo sob sensações trágicas revelaria outros saberes. "Será que não existe um reino da sabedoria, do qual a lógica está proscrita? Será que a arte não é até um correlativo necessário e um complemento da ciência?” (NIETZSCHE, 2007g, p. 89) Se, para Kant, a verdade é regulada por critérios que são válidos "para todos os conhecimentos, sem distinção dos seus objetos" (KANT, 1994, p. 93), então, quando Nietzsche transforma a própria vida em um critério de verdade, todos os fenômenos e representações se tornam válidos: validade esta que possui lógicas diferentes, pois cada vida possui sensações diferentes mesmo em situações semelhantes. Dessa forma, a sabedoria do trágico, como a canção do lírico, nada seria "exceto ele mesmo e como que tão-somente objetivações diversas de si próprio" (NIETZSCHE, 2007g, p. 42). O otimismo socrático estaria assim limitado - ao menos no campo da tragédia onde quaisquer lógicas são possíveis. E, exatamente esta limitação permitiria a criação ilimitada da própria vida. Portanto, para o jovem Nietzsche, Kant deu um importante passo para a vida e para a possibilidade de sentir o mundo tragicamente.

\section{Referências}

ARALDI, C. L.. O conflito trágico entre arte e verdade no pensamento de Nietzsche. Revista Trágica, Vol. 1, n.2, 2008.

DELEUZE, G. Nietzsche e a filosofia. Trad. Ruth Joffily e Edmundo. Fernandes Dias. Rio de Janeiro: Editora Rio, 1976.

GIACOIA Jr., O. Nietzsche $\mathbf{x}$ Kant: uma disputa permanente a respeito de liberdade, autonomia e dever. Rio de Janeiro: Casa da Palavra; São Paulo: Casa do saber, 2012.

KANT, I. Crítica da Razão Pura. Trad. de Manuela Pinto dos Santos e Alexandre Fradique Morujão. Lisboa: Ed. Fundação Caloute Gulbenkian, 1994. 
KANT, I. Crítica da faculdade do Juízo. Rio de Janeiro: Editora Universitária Forense, 2002.

LAÊRTIOS, Diôgenes. Vida e doutrina dos filósofos ilustres. Tradução do grego, introdução e notas Mário da Gama. Brasília: Editora Universidade de Brasília, 2008.

LEBRUN, G. Sobre Kant. Tradução de Rubens Rodrigues Torres Filho. São Paulo: Iluminuras, 2001.

MACHADO, R. Introdução. In: MACHADO, R. (org.). Nietzsche e a polêmica sobre $\mathbf{O}$ nascimento da tragédia. Rio de Janeiro: Jorge Zahar Editor, 2005.

MACHADO, R. Zaratustra: tragédia nietzschiana. $3^{\mathrm{a}}$ ed. Rio de Janeiro: Jorge Zahar, 2001.

NIETZSCHE, F. Schopenhauer como educador. In: Obras Incompletas. São Paulo: Ed. Abril Cultural, 1974a (Coleção Os Pensadores).

NIETZSCHE, F. Sobre Verdade e Mentira no Sentido Extra-moral. In: Obras Incompletas. São Paulo: Ed. Abril Cultural, 1974b (Coleção Os Pensadores).

NIETZSCHE, F. Kritische Studienausgabe. 15 B. - Herausgegeben von G. Colli und M. Montinari. Berlin/New York: dtv/de Gruyter, 1988.

NIETZSCHE, F. Die Geburt der Tragödie. In: Sämtliche Werke Kritische Studienausgabe. (KSA) Hrsg. G. Colli e M. Montinari. v. 1. München: Walter de Gruyter, 1988b.

NIETZSCHE, F. Nachgelassene Fragmente 1869-1874. In: Sämtliche Werke Kritische Studienausgabe. Hrsg. G. Colli e M. Montinari. v. 7. München: Walter de Gruyter, 1988c.

NIETZSCHE, F. De mi vida. Escritos autobiográficos de juventud (1856-1869). Traducción de Luis Fernando Moreno Claros. Valdemar, Madrid, 1997.

NIETZSCHE, F. Homero e a filologia clássica. Trad. de Juan Adolfo Bonaccini. Princípios, Volume 13, Números 19-20, 2006.

NIETZSCHE, F. El Nacimiento de la Tragedia. Trad. Andrés Sanches Pascual. Madrid: Alianza Editorial, 2007a.

NIETZSCHE, F. Fragmento Póstumo Nr. 12[1], da primavera de 1871. In: Discurso, no 37. Trad. Oswaldo Giacoia Junior. São Paulo: Discurso Editorial, 2007b.

NIETZSCHE, F. La visión dionisíaca del mundo. In: El Nacimiento de la Tragedia. Trad. Andrés Sanches Pascual. Madrid: Alianza Editorial, 2007c.

NIETZSCHE, F. El drama musical griego. In: El Nacimiento de la Tragedia. Trad. de Andrés Sánches Pascual. Madrid: Alianza Editorial, 2007d. 
NIETZSCHE, F. Sócrates y la tragedia. In: El Nacimiento de la Tragedia. Trad. de Andrés Sánches Pascual. Madrid: Alianza Editorial, 2007e.

NIETZSCHE, F. Cinco Prefácios para Cinco Livros Não Escritos. Trad. Pedro Süssekind. Rio de Janeiro: 7Letras, 2007f.

NIETZSCHE, F. O Nascimento da Tragédia. Tradução de J. Guinsburg. São Paulo: Companhia das Letras, 2007g.

SCHOPENHAUER, A. O mundo como vontade e como representação. Trad. Jair Barboza. São Paulo: Editora Unesp, 2005.

PERIN, A. A verdade como um problema fundamental em Kant. Revista Trans/Form/Ação, Marília, v. 33, n. 1, 2010.

PLATÃO. Fédon. São Paulo: Abril Cultural, 1973a (Coleção Os Pensadores).

PLATÃO. Sofista. Trad. Jorge Paleikat e João Cruz Costa. São Paulo: Abril Cultural, 1973b (Coleção Os Pensadores).

PLATÃO. Íon. Trad. de Victor Jabouille. Lisboa: Editora Inquérito, 1988.

PlATÃo. A República. Tradução de Anna Lia Amaral de Almeida Prado. São Paulo: Martins Fontes, 2006.

PLATÃO. Teeteto. Tradução Adriana M. Nogueira e Marcelo Boeri. Lisboa: Fundação Calouste Gulbenkian, 2010.

ROHDE, E. Resenha (recusada) para a Literarische Zentralblatt. In: MACHADO, R. (org.). Nietzsche e a polêmica sobre $O$ Nascimento da Tragédia. Trad. de Pedro Süssekind. Rio de Janeiro: Jorge Zahar Ed., 2005.

FILHO, R. R. T. Ensaios de filosofia ilustrada. São Paulo: Iluminuras, 2004. 